\title{
A Rapidly Growing Gastric Submucosal Tumor
}

\author{
Issei Hirata $^{1}$, Koji Miyahara ${ }^{1}$ and Masahiro Nakagawa ${ }^{2}$
}

Key words: fallopian tube neoplasms, follow-up care, metastasis, neoplasm, stomach

(Intern Med 60: 2503-2504, 2021)

(DOI: 10.2169/internalmedicine.6725-20)

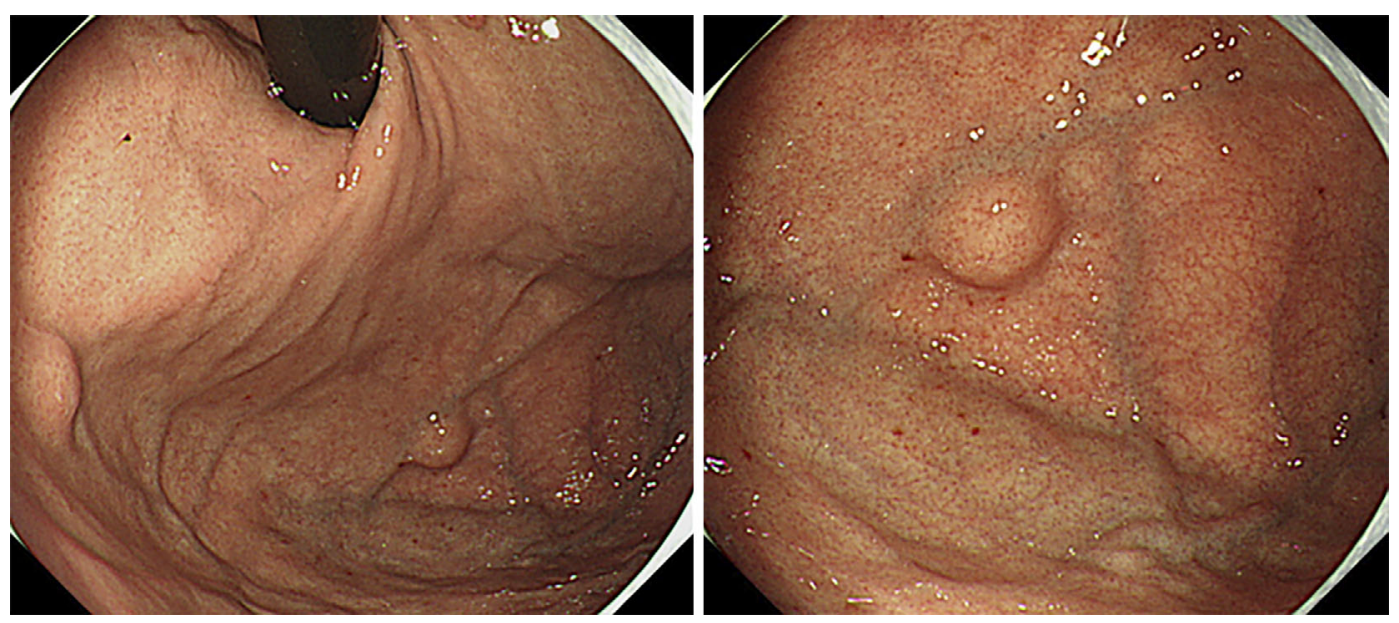

Picture 1.
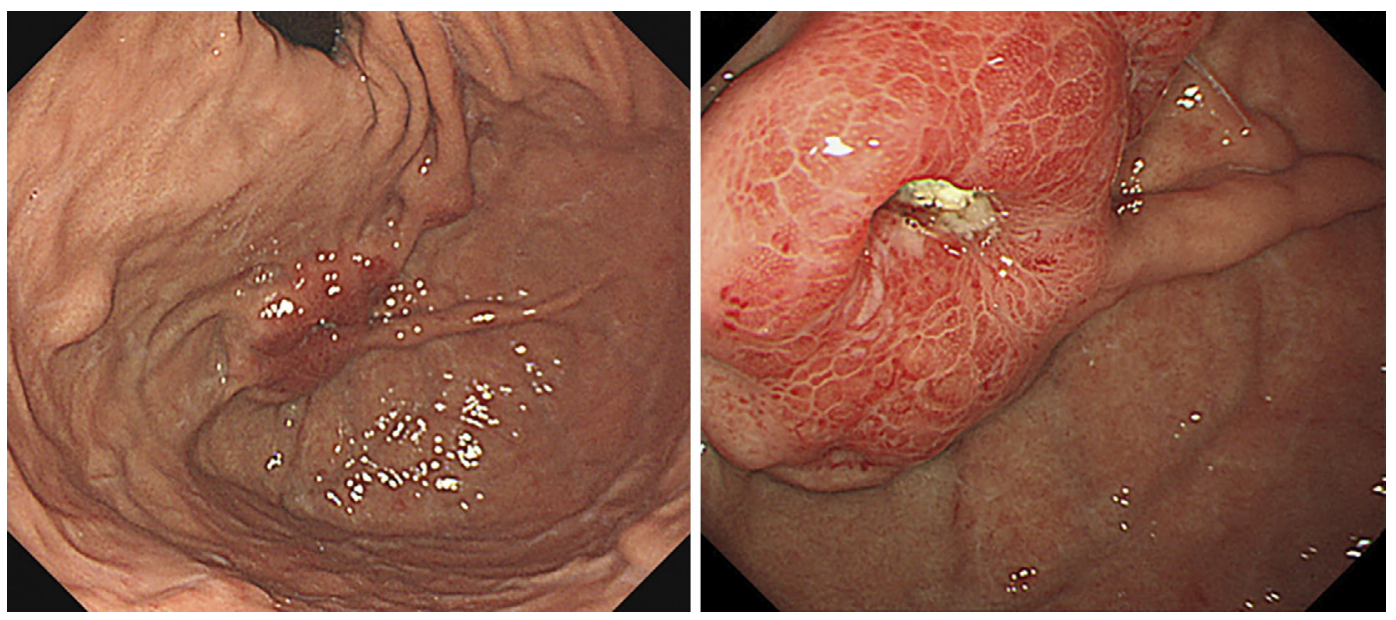

Picture 2.

A 69-year-old woman underwent esophagogastroduodenoscopy (EGD) due to abdominal pain. We identified two submucosal tumors (SMTs) measuring $<10 \mathrm{~mm}$ in size at the gastric fundus (Picture 1). A year later, follow-up EGD re- vealed that one of the lesions had rapidly grown to approximately $30 \mathrm{~mm}$ in size with ulceration (Picture 2). Biopsy specimens of the lesion indicated serous adenocarcinoma with WT1 and estrogen receptor (ER) positivity (Picture 3).

${ }^{1}$ Department of Internal Medicine, Hiroshima City Hospital, Japan and ${ }^{2}$ Department of Endoscopy, Hiroshima City Hospital, Japan Received: November 16, 2020; Accepted: December 25, 2020; Advance Publication by J-STAGE: February 15, 2021 Correspondence to Dr. Koji Miyahara, mkojisup@yahoo.co.jp 

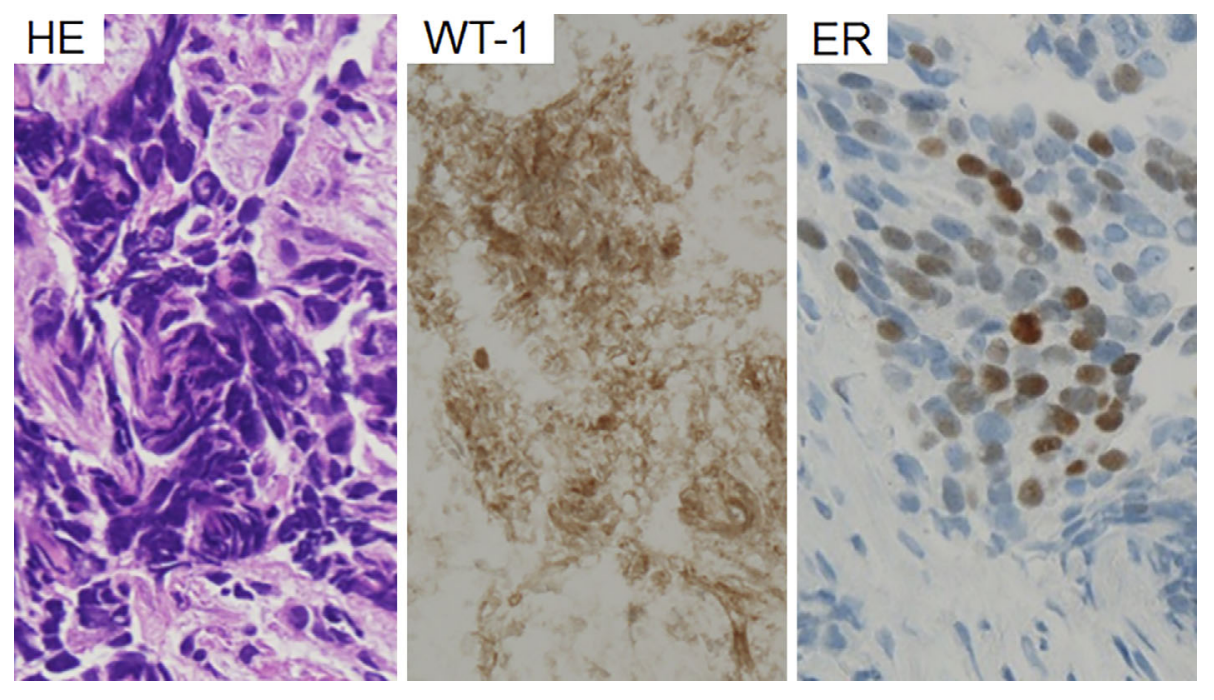

Picture 3.
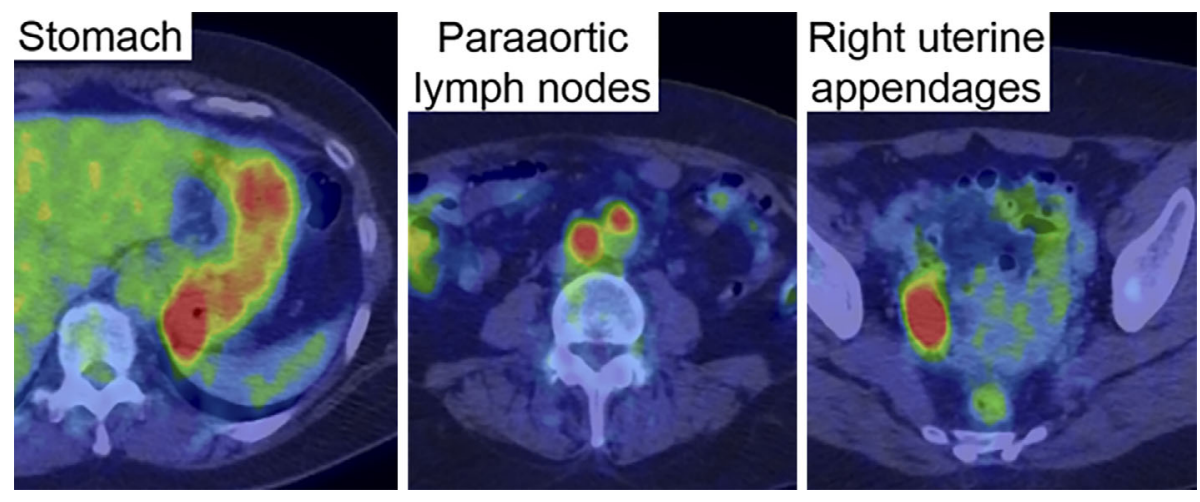

Picture 4.

After ${ }^{18} \mathrm{~F}$-fluorodeoxyglucose positron emission tomography (Picture 4), partial gastrectomy and bilateral salpingooophorectomy were performed for the diagnosis. The histology and immunoprofile of the right fallopian tube lesion were similar to those in the stomach, resulting in a final diagnosis of a metastatic gastric tumor. The other synchronous SMT did not change for 45 months after surgery. Small SMTs basically require follow-up (1); however, endoscopic ultrasonography just after the initial detection of SMTs and a "close" follow-up (e.g., 2-3 months) are preferable, considering the possibility of malignancy.
The authors state that they have no Conflict of Interest (COI).

\section{Reference}

1. Nishida T, Blay JY, Hirota S, Kitagawa Y, Kang YK. The standard diagnosis, treatment, and follow-up of gastrointestinal stromal tumors based on guidelines. Gastric Cancer 19: 3-14, 2016.

The Internal Medicine is an Open Access journal distributed under the Creative Commons Attribution-NonCommercial-NoDerivatives 4.0 International License. To view the details of this license, please visit (https://creativecommons.org/licenses/ by-nc-nd/4.0/).

(C) 2021 The Japanese Society of Internal Medicine Intern Med 60: 2503-2504, 2021 